can the tonsils reveal. A literature review. Int $J$ Pediatr Otorhinolaryngol. 2020;130. doi:10.1016/j.jporl.2019.109795

[6] Gidron Y, Berkovitch M, Press J. Psychosocial correlates of incidence of attacks in children with Familial Mediterranean Fever. J Behav Med. 2003;26(2):95-104. doi:10.1023/A:1023038504481

[7] Makay B, Emiroğlu N, Ünsal E. Depression and anxiety in children and adolescents with familial Mediterranean fever. Clin Rheumatol. 2010;29(4):375379. doi:10.1007/s10067-009-1330-9

[8] Kraszewska-Głomba B, Matkowska-Kocjan A, Szenborn L. The Pathogenesis of Periodic Fever, Aphthous Stomatitis, Pharyngitis, and Cervical Adenitis Syndrome: A Review of Current Research. Mediators Inflamm 2015;2015:563876. doi:10.1155/2015/563876

Disclosure of Interests: None declared

DOI: 10.1136/annrheumdis-2021-eular.706

\section{POS1295 PERFORMANCE OF 2019 EULAR/ACR CLASSIFICATION CRITERIA FOR SYSTEMIC LUPUS ERYTHEMATOSUS IN A PEDIATRIC POPULATION - A MULTICENTER STUDY}

Y. Levinsky, ${ }^{1,2}$, M. Broide ${ }^{1}$, S. Kagan ${ }^{1}$, O. Goldberg ${ }^{1}$, O. Scheuerman ${ }^{1}$, R. Tal ${ }^{3}$, I. Tirosh ${ }^{4}$, Y. Butbul ${ }^{5}$, L. Harel ${ }^{2,3}$, G. Amarilyo ${ }^{2,3} .{ }^{1}$ Schneider Children's Medical Center of Israel, Pediatrics, Petach Tikva, Israel; ${ }^{2}$ Tel Aviv University, Tel Aviv, Israel, Sackler Faculty of Medicine, Tel Aviv, Israel; ${ }^{3}$ Schneider Children's Medical Center of Israel, Pediatric Rheumatology Unit, Petach Tikva, Israel; ${ }^{4}$ Sheba Medical Center, Tel Hashomer, Pediatric Rheumatology Service, Edmond and Lily Safra Children's Hospital, Ramat Gan, Israel; ${ }^{5}$ Rambam Health Care Campus, Haifa, Israel, Pediatric Rheumatology Service, Ruth Rappaport Children's Hospital, Haifa, Israel

Background: The "European League Against Rheumatism" and "American College of Rheumatology" 2019 (EULAR/ACR-19) criteria for the diagnosis of Systemic Lupus Erythematosus (SLE) were recently published, with the stated goal of maintaining the level of sensitivity and raising the level of specificity for classification of SLE in adults.

Objectives: We aimed to examine the function of the new EULAR/ACR-19 criteria in a population of children and compare them to the SLICC-12 and ACR-97 criteria.

Methods: In this multicenter study the charts of jSLE patients from three tertiary medical centers were reviewed and compared to patients with non-jSLE diagnosis. Pediatric rheumatologists, blinded to the original diagnosis, reviewed and diagnosed all cases. Pediatric patients' clinical and laboratory data were retrospectively extracted and then examined with regard to how they met the new and old criteria.

Results: Included were 225 patients (112 jSLE, 113 non-SLE). When applied to juvenile SLE classification, the sensitivity of the new EULAR/ACR-19 criteria was $0.96(0.9-.0 .99)$ and the specificity was $0.89(0.82-0.94)$. These were comparable to the Systemic Lupus International Collaborating Clinics (SLICC) criteria. The sensitivity of the EULAR/ACR-19 criteria improves over time and was 0.83 twelve months following disease onset, reaching 0.96 after longer than 24 months. Conclusion: Among a cohort of jSLE patients, sensitivity of the new EULAR/ ACR-19 criteria was found to be high and specificity may have improved slightly compared to the SLICC-12 criteria. We support the use of the new classification criteria for pediatric patients in future jSLE studies, but it should be noted that its specificity is lower than for adults.

\begin{tabular}{lcll}
\hline & \multicolumn{1}{c}{ ACR-97 } & \multicolumn{1}{c}{ SLICC-12 } & \multicolumn{1}{c}{$\begin{array}{c}\text { EULAR/ } \\
\text { ACR-19 }\end{array}$} \\
\hline Sensitivity $(95 \% \mathrm{Cl})$ & $0.79(0.70-0.86)$ & $0.96(0.9-0.99)$ & $0.96(0.9-0.99)$ \\
Specificity $(95 \% \mathrm{Cl})$ & $0.94(0.88-0.97)$ & $0.85(0.77-0.91)$ & $0.89(0.82-0.94)$ \\
Accuracy $(95 \% \mathrm{Cl})$ & $0.86(0.81-0.9)$ & $0.9(0.86-0.94)$ & $0.92(0.88-.0 .96)$ \\
Positive Likelihood Ratio $(95 \% \mathrm{Cl}) 12.7(6.1-26.2)$ & $6.35(4.1-9.9)$ & $9.0(5.3-15.4)$ \\
Negative Likelihood Ratio & $0.23(0.16-0.33)$ & $0.05(0.02-0.12)$ & $0.05(0.02-0.12)$ \\
$\quad(95 \% \mathrm{Cl})$ & & & \\
Diagnostic odds ratio $(95 \% \mathrm{Cl})$ & $55.5(22.80-135.0)$ & $120.85(43.0-340.0)$ & $180.1(61.3-529.4)$
\end{tabular}

\section{REFERENCES:}

[1] Smith EMD, Lythgoe H, Midgley A, Beresford MW, Hedrich CM. Juvenile-onset systemic lupus erythematosus: Update on clinical presentation, pathophysiology and treatment options. Clin Immunol 2019 published on December 2019. doi: 10.1016/..clim.2019.108274

[2] Massias JS, Smith EMD, Al-Abadi E, Armon K, Bailey K, Ciurtin C, et al. Clinical and laboratory characteristics in juvenile-onset systemic lupus erythematosus across age groups. Lupus 2020;29(5):474-81.
[3] Hochberg MC. Updating the American College of Rheumatology revised criteria for the classification of systemic lupus erythematosus. Arthritis Rheum. 1997 Sep;40(9):1725

[4] Petri M, Orbai AM, Alarcõn GS, Gordon C, Merrill JT, Fortin PR, et al. Derivation and validation of the systemic lupus international collaborating clinics classification criteria for systemic lupus erythematosus. Arthritis Rheum 2012 Aug;64(8):2677-86

[5] Hartman EAR, van Royen-Kerkhof A, Jacobs JWG, Welsing PMJ, FritschStork RDE. Performance of the 2012 Systemic Lupus International Collaborating Clinics classification criteria versus the 1997 American College of Rheumatology classification criteria in adult and juvenile systemic lupus erythematosus. A systematic review and meta-an. Autoimmun Rev. 2018;17(3):316-22.

[6] Aringer M, Costenbader K, Daikh D, Brinks R, Mosca M, Ramsey-Goldman R, et al. 2019 European League Against Rheumatism/American College of Rheumatology Classification Criteria for Systemic Lupus Erythematosus. Arthritis Rheumatol 2019;71(9):1400-12.

Disclosure of Interests: None declared

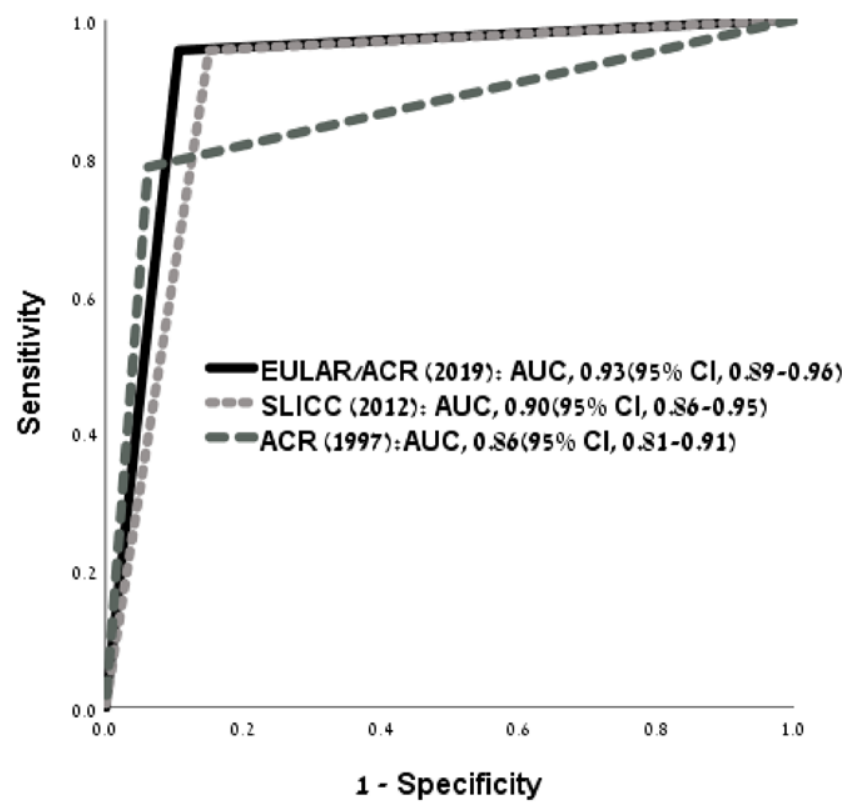

DOI: 10.1136/annrheumdis-2021-eular.708

\section{POS1296 \\ JIA PATIENTS DO NOT HAVE MORE OSTEOPOROSIS THAN HEALTHY AGE AND SEX-MATCHED CONTROLS BUT LOWER BONE MASS DENSITY IS FOUND AT TOTAL HIP AND CORTICAL COMPARTMENT}

M. Lopez Corbeto ${ }^{1}$, M. Barcelo Bru², E. Moreno Ruzafa ${ }^{1}$, M. Pasqual Pastor ${ }^{2}$. ${ }^{1}$ Vall d'Hebron University Hospital, Pediatric Rheumatology, Barcelona, Spain; ${ }^{2}$ Vall d'Hebron University Hospital, Rheumatology, Barcelona, Spain

Background: Achievement of a normal peak bone mass is an especially important consideration in young adults with juvenile idiopathic arthritis (JIA), because interference with attainment of peak bone mass may not be repaired later in life. It has been suggested that children with JIA cortical appendicular skeletal bone is more affected by disease activity than axial trabecular bone. To evaluate bone mineral density (BMD) DXA measurements are widely used. Although, DXA is limited to two-dimensional evaluation of integral BMD and cannot differentiate between trabecular and cortical bone compartments. Alternatively, 3D-DXA analysis is a new method based on DXA scans of proximal femur that provides accurate estimates of trabecular and cortical volumetric BMD.

Objectives: The aim of the study was to analyze the trabecular and cortical bone using 3D-DXA in young adults with JIA compared to age-matched healthy controls.

Methods: This cross-sectional study was aimed to analyze the differences in 3D-DXA proximal femur compartments. The patients were recruited from the specialized transitional unit of the Vall d'Hebron University Hospital. JIA patients older than 18 yo without previous bisphosphonates intake were included. Age and sex-matched healthy controls were selected. DXA scans (Lunar Prodigy, General Electric Medical Systems, v.15) were acquired. OP was defined according to the WHO criteria. The 3D-DXA software was used to assess in 3D the trabecular density and cortical thickness from DXA scans as reported previously 
[1]. The 3D-DXA and DXA measurements were compared using Student's $t$ test. Categorical variables were compared using Chi-squared test. All hypothesis tests with $p$ value lower than $5 \%$ were considered significant.

Results: Forty-six patients and 46 age and sex-matched controls were evaluated. The mean time of disease's duration was 7.37 years, and the most frequent JIA subtype was Oligoarticular ANA positive. More than $21 \%$ of the patients had an active disease. OP was present in 5 patients and 1 control. Despite not finding significant differences in the prevalence of osteoporosis, JIA patients had lower aBMD at total hip by DXA and lower cortical SBMD by 3D-DXA than controls (Table 1).

Table 1. Comparison of DXA and 3D-DXA measurements between JIA and healthy controls

\begin{tabular}{llll}
\hline Variable & JIA patients $(\mathrm{n}=46)$ & $\begin{array}{l}\text { Healthy controls } \\
(\mathrm{n}=46)\end{array}$ & $\begin{array}{l}P \\
\text { value }\end{array}$ \\
\hline DXA & & & \\
Lumbar aBMD $\left(\mathrm{g} / \mathrm{cm}^{2}\right)$, mean $\pm \mathrm{sd}$ & $1.097 \pm 0.02$ & $1.155 \pm 0.02$ & 0.042 \\
Right femoral neck aBMD $\left(\mathrm{g} / \mathrm{cm}^{2}\right)$, mean $\pm \mathrm{sd}$ & $0.930 \pm 0.02$ & $1.014 \pm 0.01$ & 0.041 \\
Right total hip aBMD $\left(\mathrm{g} / \mathrm{cm}^{2}\right)$, mean $\pm \mathrm{sd}$ & $0.932 \pm 0.02$ & $1.001 \pm 0.01$ & $\mathbf{0 . 0 0 8}$ \\
Lumbar T-score, mean $\pm \mathrm{sd}$ & $-0.716 \pm 0.16$ & $-0.212 \pm 0.16$ & 0.037 \\
Right femoral neck T-score, mean $\pm \mathrm{sd}$ & $-0.563 \pm 0.17$ & $0.087 \pm 0.12$ & 0.036 \\
Right total hip T-score, mean $\pm \mathrm{sd}$ & $-0.721 \pm 0.18$ & $-0.12 \pm 0.13$ & 0.008 \\
3D-DXA & & & \\
Trabecular vBMD $\left(\mathrm{mg}^{\prime} / \mathrm{cm}^{3}\right)$, mean $\pm \mathrm{sd}$ & $180.44 \pm 5.54$ & $194.57 \pm 5.11$ & 0.064 \\
Cortical sBMD $\left(\mathrm{mg} / \mathrm{cm}^{2}\right)$, mean $\pm \mathrm{sd}$ & $147.23 \pm 3.41$ & $161.52 \pm 2.89$ & $\mathbf{0 . 0 0 2}$ \\
Osteoporosis $(\mathrm{WHO}$ definition) & & & \\
Yes, $\mathrm{n}(\%)$ & $5(10.87)$ & $1(2.17)$ & 0.091 \\
No, $\mathrm{n}(\%)$ & $41(89.13)$ & $45(97.83)$ & \\
\hline
\end{tabular}

$D X A$ dual-energy $X$-ray absorptiometry, $s d$ standard deviation, $a B M D$ areal bone mineral density, $3 D-D X A$ three-dimensional dual-energy $\mathrm{X}$-ray absorptiometry, $v B M D$ volumetric bone mineral density, $S B M D$ superficial cortical bone mineral density

Conclusion: JIA patients do not have more OP than controls in our cohort but there are differences in BMD in the different locations and greater involvement of the cortical bone in JIA.

REFERENCES:

[1] Brance ML, et al. Trabecular and cortical bone involvement in rheumatoid arthritis by DXA and DXA-based 3D modelling. Osteoporos Int, 2020 Sep 24.

Disclosure of Interests: None declared

DOI: 10.1136/annrheumdis-2021-eular.742

\section{POS1297 $\quad$ HOW HLA B27 PREVALENCE IN THE POPULATION INFLUENCE ON FEATURES OF JUVENILE IDIOPATHIC ARTHRITIS: DATA FROM SAKHA REPUBLIC (YAKUTIA)}

F. Vinokurova ${ }^{1}$, L. Sorokina ${ }^{2}$, V. Argunova ${ }^{3}$, P. Sleptsova ${ }^{3}$, T. Bourtseva ${ }^{4,5}$, V. Chasnyk ${ }^{2}$, M. Kostik ${ }^{2}{ }^{1}$ Yakut Science Center of Complex Medical Problems, Laboratory of Immunological Researches, Yakutsk, Russian Federation; ${ }^{2}$ Saint-Petersburg State Pediatric Medical University, Department of Hospital Pediatrics, St. Petersburg, Russian Federation; ${ }^{3}$ Republic Hospital № 1 - National Center of Medicine, Pediatric Center, Department of CardioRheumatology, Yakutsk, Russian Federation; ${ }^{4}$ North-Eastern Federal University (NEFU), Department of Pediatrics and Pediatric Surgery of Medical Institute NEFU, Yakutsk, Russian Federation; ${ }^{5}$ Yakut Science Center of Complex Medical Problems, Laboratory of Children Health Monitoring and Medical and Environmental Research, Yakutsk, Russian Federation

Background: Sakha Republic (Yakutia) - SR(Y) is a bid arctic region of Russia with high proportion of aboriginals - Yakutians (50\%), intra-national marriages, increased level of inbreeding and high distribution of HLAB27 among aboriginals $-33 \%$, according the epidemiological studies. The main type of arthritis is ankylosing spondylitis in adults and enthesytis-related arthritis (ERA) of juvenile idiopathic arthritis (JIA) in children. The pattern of arthritis distribution in adults and children in $\mathrm{SR}(\mathrm{Y})$ is differ from Caucasians and similar to Native Americans.

Objectives: Our study aimed to evaluate the features of JIA in aboriginals of $\mathrm{SR}(\mathrm{Y})$, associated with high prevalence of HLAB27 antigen.

Methods: In the retrospective study we included 144 Yakutians who were admitted in the rheumatology department of Yakutsk in 2007-2016 years and $753 \mathrm{JIA}$ patients Caucasian origin in Saint-Petersburg in the same years. We evaluated routine clinical and laboratorial features. HLA B27 was evaluated according the clinical judgement of the attending physicians.

Results: ERA is a main JIA category in Yakutians. The main features the male predominance, higher onset age, high inflammatory activity, lower number of active joints, high incidence of hip and sacroiliac joints involvement, lower levels of psoriasis and uveitis. Yakutians have rare the involvement of cervical spine ( $6 \%$ vs $14 \%$, $\mathrm{p}=0.0000001)$, TMJ ( $1 \%$ vs $6 \%, p=0.027)$, elbow ( $8 \%$ vs $16 \%, p=0.012)$, wrist $(18 \%$ vs $28 \%, p=0.017$ ), MCP ( $7 \%$ vs $21 \%, p=0.00005)$, PIP ( $8 \%$ vs $25 \%, p=0.00005$ ). The treatment rates of methotrexate and biologics were similar between groups, but in Yakutians the biologics were administered earlier, because methotrexate failed and often was ineffective. The cumulative probability to receive biologics was higher in Yakutians compare to Caucasians: HR=3.4 [2.6; 4.4], $\mathrm{p}=0.000001$ (Figure 1). The main biologic in Yakutians was etanercept (49/70; 70\%). Yakutians received corticosteroids and cyclosporine $A$ rarely, due to low incidence of systemic onset JIA and oligoarthritis with uveitis. It was observed, that the HLA B27 as a risk factors had different significance in Yakutians and Caucasians. HLA B27 presence increased the risk of $E R A O R=2.72(1.3 ; 5.6) p=0.01$ in Yakutians and $O R=69.2(29.5 ; 162.3)$ $p=0.00001$ for Caucasians; for biologic administration: $0,86(0,4 ; 1,8), p=0.529$ and $2,45(1,5 ; 4,0), p=0.0003$, respectively.

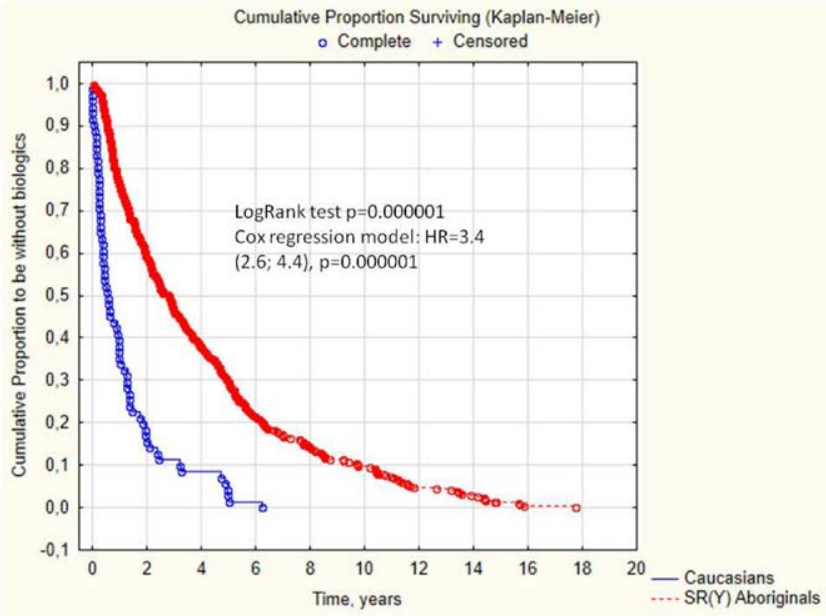

Figure 1. Cumulative probability to leave without biologics between Yakutian and Caucasian JIA patients.

Conclusion: High distribution of HLA B27 antigene in Yakutians, lead to different pattern of JIA categories distributions and patient's management.

This work was supported by the Project of the Ministry of Science and Higher Education of the Russian Federation (basic part of funding to M.K. Ammosov North-Eastern Federal University \#FSRG-2020-0016) and by the RFBR gran \#18-05-600035 Arctika.

Table 1. Differences between Yakutian and Caucasian JIA patients.

\begin{tabular}{|c|c|c|c|}
\hline JIA features & Yakutians, n=144 (\%) & Caucasians, n=723 (\%) & p \\
\hline Gender, boys, n (\%) & $85(59.0)$ & $279(38.6)$ & 0.000006 \\
\hline $\begin{array}{l}\text { Onset age, years } \\
\text { JIA categories, } n(\%)\end{array}$ & $10.6(6.0 ; 13.4)$ & $6.0(3.0 ; 10.3)$ & 0.0000001 \\
\hline Oligoarthritis & $36(25.0)$ & $188(26.0)$ & 0.0000001 \\
\hline Poly, RF (-) & $21(14.6)$ & 248 (34.3) & \\
\hline Poly, RF (+) & $1(0.7)$ & $22(3.0)$ & \\
\hline Systemic onset & $4(2.8)$ & $53(7.3)$ & \\
\hline ERA & $76(52.8)$ & $171(23.7)$ & \\
\hline Psoriatic arthritis & $6(4.2)$ & $41(5.7)$ & \\
\hline Active joints & $4.0(3.0 ; 6.0)$ & $6.0(3.0 ; 12.0)$ & 0.0000001 \\
\hline Uveitis, n (\%) & $16(11.1)$ & $114 / 503(22.7)$ & 0.002 \\
\hline Psoriasis, $\mathrm{n}(\%)$ & $3 / 143(2.1)$ & $46 / 719(6.4)$ & 0.043 \\
\hline Hip involvement & $50(34.7)$ & $146(20.2)$ & 0.0001 \\
\hline Sacroiliitis & 46 (31.9) & $69(9.6)$ & 0.0000001 \\
\hline HLA B27, n (\%) & $76 / 131(58.0)$ & 105/301 (34.8) & 0.00001 \\
\hline ANA, n (\%) & $4 / 46(8.7)$ & 204/444 (46.0) & 0.00001 \\
\hline $\mathrm{RF}, \mathrm{n}(\%)$ & $3 / 141(2.1)$ & $22 / 403(5.5)$ & 0.104 \\
\hline Biologics, primary, n (\%) & 70/144 (48.6) & $347(48.0)$ & 0.892 \\
\hline Time before first biologics, years & $0.6(0.3 ; 1.4)$ & $2.6(1.0 ; 5.4)$ & 0.0000001 \\
\hline
\end{tabular}

Disclosure of Interests: None declared

DOI: 10.1136/annrheumdis-2021-eular.810

\section{POS1298 COMPARISON OF FMF CLINICAL FEATURES} BETWEEN TURKISH AND CRIMEAN TATAR CHILDREN

O. Zhogova ${ }^{1}$, U. Kaya Akca ${ }^{2}$, E. Suspitsin ${ }^{3,4}$, E. Sag ${ }^{2}$, V. Nizhnik ${ }^{3}$, A. Tumakova ${ }^{3}$ S. Ivanoskiy ${ }^{1}$, N. Lagunova ${ }^{1}$, Y. Bilginer ${ }^{2}$, S. Özen ${ }^{2}$, M. Kostik ${ }^{3,5}$. ${ }^{1}$ Crimean Federal University named after V.I. Vernadsky, Pediatry, Simferopol, Russian Federation; ${ }^{2}$ Hacettepe University, Department of Pediatric Rheumatology, Faculty of Medicine, Ankara, Turkey; ${ }^{3}$ Saint Petersburg State Pediatric Medical University, Hospital Pediatry, Saint-Petersburg, Russian Federation; ${ }^{4}$ N.N. Petrov National Research Center of Oncology, Molecular Diagnostics, SaintPetersburg, Russian Federation; ${ }^{5}$ Almazov National Medical Research Centre, 